\title{
Tweeting Outside the Lines: Normalization and Fragmentation as Political Reporters Break from the Mainstream
}

\section{Rachel R. Mourão \& Logan Molyneux}

To cite this article: Rachel R. Mourão \& Logan Molyneux (2020): Tweeting Outside the Lines: Normalization and Fragmentation as Political Reporters Break from the Mainstream, Journalism Practice, DOI: $10.1080 / 17512786.2020 .1771753$

To link to this article: https://doi.org/10.1080/17512786.2020.1771753

+ View supplementary material $₫$

\section{Published online: 31 May 2020.}

5 Submit your article to this journal

\section{Article views: 84}

Q View related articles $\widetilde{ }$ 


\title{
Tweeting Outside the Lines: Normalization and Fragmentation as Political Reporters Break from the Mainstream
}

\author{
Rachel R. Mourão $\mathbb{D}^{\mathrm{a}}$ and Logan Molyneux (D) \\ ${ }^{\mathrm{a} S}$ School of Journalism, Michigan State University, East Lansing, MI, USA; ${ }^{\mathrm{b}}$ Department of Journalism, Temple \\ University, Philadelphia, PA, USA
}

\begin{abstract}
The field of journalism is experiencing intense diversification in form and message while trying to overcome widespread public disaffection by reinforcing professional norms. This study focuses on two forces-normalization and fragmentation-by observing them at work on social media. We analyzed content and interactions from mainstream and non-mainstream political journalists covering a 2016 U.S. presidential debate. Forces of normalization would draw these two groups of reporters together in a monolithic, widespread practice, perhaps including both newer and older methods. Forces of fragmentation, on the other hand, would drive groups of practitioners further apart, with clearer lines separating mainstream journalism from its offshoots. The key question is where these similarities and differences between mainstream and non-mainstream journalists arise. Findings suggest divergence in objectivity and gatekeeping, and convergence in campaign coverage practices. The evidence suggests that, on Twitter, mainstream reporters insulate themselves by interacting mainly with other journalists, while nonmainstream journalists offer openly partisan interpretations and seek out audience participation and engagement, often from people sharing their viewpoints.
\end{abstract}

\section{KEYWORDS}

Normalization; fragmentation; social media; journalism; political communication; elections

In the study of social fields, scholars observe that the status quo has tremendous pull in structuring action (Bourdieu 1986; Ryfe 2016), a process that has been called "normalization." Uncertainty leads emerging actors to pursue public legitimacy by seeking stability and validation within established norms. This process draws both new and old members of the field toward centralized standards, which may incorporate newer practices alongside older ones (Singer 2005; Lasorsa, Lewis, and Holton 2012; Molyneux and Mourão 2019). However, once the field is constituted, its members fend off incursions from outsiders by normalizing rules and maintaining boundaries across the entire group. If this process fails, the field becomes unrecognizable.

This is clearly visible in the field of journalism. Weakened by economic, cultural and technological forces, mainstream journalism is experiencing centrifugal diversification in form, source, message and norms. This force pushes political communication away from 
a central core and toward fragmentation and tailoring of messages to particular identities (Blumler and Kavanagh 1999; Blumler 2016). This process, known as "fragmentation," has many manifestations, but the worldwide uproar since 2017 over journalistic integrity and the authenticity of news reports typifies the difficulties that arise when work by those outside the field is not easily distinguishable from work by those within it (Carlson 2018; Tandoc, Jenkins, and Craft 2019). In short, the field has become less homogeneous as insurgent actors present themselves (and are treated by audiences and sectors of the political elite) as journalists.

This study focuses on the tension between these two forces-normalization and fragmentation-driving political journalism toward an entropic state where both old norms and elements exogenous to the profession are practiced in different measures by different groups, all under a broadening umbrella of journalism. But journalists, like professionals in other fields, act in opposition to perceived threats to maintain boundaries (Lewis 2012), creating both mainstream and non-mainstream groups within the same social field. By observing which practices mainstream journalists adopt and which they reject, it is possible to know what they see as the core elements that structure and differentiate their profession.

Here, it is important to acknowledge that these non-mainstream producers are largely rejected by current members of the field, who act towards "expulsion" (see Lewis and Carlson 2015). Our argument is that this does not, however, preclude these producers from challenging and potentially reshaping the field in many ways. Beyond journalism circles, the distinction is much less clear, particularly to audiences who rely on them for information. These challengers are further legitimized by sectors of the political elite, who grant them various markers of journalistic authority (access via press passes, interviews, promoting their content, etc.) (Jamieson and Cappella 2010).

Simultaneously, publishers such as Breitbart, Blue Nation Review and Washington Examiner position themselves as journalistic organizations operating outside the mainstream flow. They style themselves as news organizations and are treated as such by their audiences, but follow noticeably different practices. Indeed, these organizations' self-descriptions emphasize "destruction of the political/media establishment" and purport to offer the "news" and "factual content" mainstream media "deceptively" overlook or report with "bias" and "slant" (see Appendix 1). Hereafter we refer to employees of these organizations as "non-mainstream journalists" because they strategically mix emerging practices with established journalistic norms and formats in efforts to legitimize.

This project seeks to determine whether theoretically expected and organizationally professed differences in ethos are observable in the practices of non-mainstream journalists. It does so by observing forces of normalization and fragmentation on social media, where previous literature suggests they are already strongly at work (Lasorsa et al. 2012; Molyneux, Mourão, and Coddington 2016; Molyneux and Mourão 2019). But whereas these previous studies treated political reporters as a homogeneous group following a neo-institutional approach (Cook 1998), this study compares practices of journalists at mainstream news organizations with those of journalists working for outlets that describe themselves as offering news with an anti-mainstream press rhetoric. The overarching research questions guiding this study are: How do the practices of non-mainstream journalists compare with those of mainstream reporters? How are these practices shaped by forces of normalization and fragmentation? 
These questions are answered through a content analysis of tweets and digital trace data produced by political reporters working for selected mainstream and non-mainstream outlets during the first U.S. presidential debate in 2016. If these two groups produce a homogeneous stream of content, that would suggest practices have normalized, or become standardized and widely adopted; divergence in the groups' practices would indicate varying degrees of fragmentation. The future constitution of the field will depend on how these forces are reconciled (Carlson and Lewis 2015).

\section{Normalization}

The word normalization as used here describes the process by which commonly held standards are established and spread across a group -in this case, professional journalists. It signifies the ways in which journalists perceive which practices are "normal" in their profession. Normalization suggests that the status quo has enormous weight, and that while small changes are possible, it is difficult to enact broad shifts in a professional field's norms and practices. While field members may not articulate specific norms as they work to defend them, a range of actions may be interpreted as boundary maintenance (for journalistic cases, see Robinson 2010; Coddington 2012).

Recently, studies of journalism have used the term "normalization" to encompass tendencies that largely replicate existing norms and structures while making some adjustments in response to new media. Studies of blogs (Singer 2005) and social media (Lasorsa, Lewis, and Holton 2012) have found that journalists most often seem to transfer old norms to new media, rather than developing entirely new practices centered around new media affordances. While minor negotiations of norms and values can occur as a result of innovations or disruptive entrants into the field, major restructuring is extremely difficult (Ryfe 2016).

It is crucial to note that we use the term "normalization" here to describe a process of socialization (or professionalization) recognized within the fields of journalism studies and political communication. We acknowledge that the term is also used in cultural studies and media sociology to refer to ways in which journalism serves as a conduit for larger ideological forces. For example, recent work addressed how journalistic norms can aid in the normalization of right-wing populist candidacies in the Americas (Parks 2019; Araújo and Prior 2020).

Normalization (as professionalization) is particularly important in journalism for several reasons (Ryfe 2016). First, in the absence of formal licensing procedures or common bodies of knowledge (as in medicine or law), membership in the field of journalism is defined by adherence to established journalistic practices and shared narrative-construction of events (Zelizer 1993). Second, expertise in professional fields accrues with experience and proficiency in certain skills, which helps ensure these skills are perpetuated (Schultz 2007). Finally, much of journalists' training occurs through processes of social control and ritual interactions, and these tend to reproduce (rather than restructure) rules of conduct.

Another way of looking at forces of normalization is through ecological lenses, as elaborated by Lowrey (2012). Given wide variation in form and practice, new practices are selected, or stabilize, into populations as their practitioners seek acceptance and legitimacy and look to reduce uncertainty (Scott 2008). These processes, routines, norms and values predate and endure technological changes (Cook 2006). 
Evidently, a tendency toward normalization has characterized some substantial portion of journalism's path on Twitter, but it does not account for everything. Within mainstream journalism, some new ideas, forms and practices have taken hold (e.g., Hermida, Lewis, and Zamith 2014); beyond the mainstream, Blumler and Kavanagh (1999) expect we would see a range of experimental forms competing for attention and legitimacy. Therefore, we must consider a second force that accounts for the diversity of products and messages in contemporary news media.

\section{Fragmentation}

The institutional approach was developed to describe a press that operated in an era where mass media offered relatively little choice (Blumler and Kavanagh 1999) and, despite the proliferation of channels and actors in the 1990s, Cook (2006) argued that there was still an elite mainstream media that had access to public officials and that gave legitimacy to political players.

But much has changed in the last decade. New unconventional players emerged and gained access (e.g., Infowars gaining press passes), traditional outlets were scorned publicly by officials, mainstream reporters lost access, partisan media entered the mainstream and the government, and trust in the press reached its lowest point ever (Swift 2016). Simultaneously, an anti-mainstream media identity fueled the establishment of a powerful partisan apparatus that shapes interpretations of events and influences the policies and rhetoric of the Republican Party (Jamieson and Cappella 2008).

Blumler and Kavanagh (1999) describe the beginnings of this new phase of political communication as marked by the proliferation of media channels and the tailoring of communication to particular identities, including the rise of populist and anti-establishment leaders who scorn the mainstream press. On the supply side, one important trend is genre-blending; that is, the discursive integration of elements from news, fiction and entertainment in political communication (Baym 2010; Mourão and Robertson 2019).

This proliferation of channels and audience fragmentation has led some scholars in the early 2000s to argue the concept of "mass media" and its related theories are insufficient to explain political communication, marking the beginnings of a "new era of minimal effects" (Chaffee and Metzger 2001; Bennett and lyengar 2008). More recent evidence, however, indicates that top-down processes-with differential power structures that privilege mainstream channels, official sources and political elites-are still very much at play despite technology-fueled fragmentation (Holbert, Garrett, and Gleason 2010; Djerf-Pierre and Shehata 2017; Robinson 2017; Gutsche and Hess 2018a, 2018b).

After the 2016 U.S. presidential election, a new genre of news-like hybrid captured popular attention, with so-called "fake news" blurring the lines between factual and non-factual information. The term is commonly used post-2016 to refer to stories that resemble news formats but contain misinformation intended to deceive (Tandoc, Lim, and Ling 2018). Organizationally, websites like the ones we analyze in this paper present themselves as news providers, while often recognizing their biases (Robertson \& Mourão 2020). The challenge posed by these new actors is widely acknowledged by professional journalists as a critical incident influenced by the logics and economics behind social media platforms (Carlson 2018; Tandoc, Jenkins, and Craft 2019). 
In this paper, we argue that studying the output of those working for these non-mainstream media should involve holistic approaches that combine old and new media, identifying areas where discrepancies matter and those where they are dissolving (Chadwick 2017). Processes of boundary drawing, boundary blurring and boundary crossing characterize political newsmaking, and the logics of older and newer media compete and coevolve (Carlson and Lewis 2015). Only through analysis of discrete practices and moments of interaction will scholars be able to identify the conditions under which journalistic practice is influenced by "old" or "new" media practices (Chadwick 2017).

\section{Journalistic Practices on Twitter}

To find evidence of the forces of normalization and fragmentation, this study examines political journalists' use of Twitter. This setting is appropriate because previous research has observed forces of normalization, fragmentation, and negotiation in this emerging space (Molyneux, Holton, and Lewis 2018). Our paper aims to add to this body of work by comparing mainstream journalists with "reporters" who work for sites that self-identify as journalistic but also external to the mainstream media (often confrontationally). In other words, while divisions in ethos between mainstream and non-mainstream journalists are theorized by scholars and proclaimed by the outlets themselves, we focus on what similarities and differences can be observed in practice. We study the content posted by journalists on one platform as a reflection of the practices behind its production, employing a media sociology assumption that sees tweets as the output of newsmaking processes (Shoemaker and Reese 2014). Here, our argument is that practices are guided by different norms and predict the differences we are seeing in content. In addition to the manifest content of journalists' tweets, we also capture and analyze digital trace data of interactions with other users on Twitter as direct evidence of journalistic practice. Together, the content and interactions on Twitter provide a more complete observation of journalistic practice. Using a comparison between two groups to make inferences about practice differences mirrors prior normalization studies (e.g., Lasorsa, Lewis, and Holton 2012) that compared the Twitter output of different types of reporters.

It is important to note that the groups chosen for this comparison were driven by our theoretical interest in a particular splinter of journalistic practice. That is, we use traditional mainstream media as the "reference" against which we compare the practices of nonmainstream reporters. This reference choice reflects prior work focusing on mainstream newsrooms in the United States, but we acknowledge that variations might occur if this study had compared the practices of non-mainstream reporters internationally (Mourão and Chen 2020), over time (Djerf-Pierre, Ghersetti, and Hedman 2016), or to those of alternative journalism (Harlow and Johnson 2011).

The first research question addresses the use of technological affordances provided by the platform itself:

RQ1: How do mainstream and non-mainstream journalists compare when it comes to their use of (a) original tweets, (b) retweets, (c) replies, and (d) block quotes?

Next, we turn to the literature on Twitter and campaign reporting. This literature has focused mainly on three aspects of reporters' adoption of Twitter for political coverage: 
protection of gatekeeping, objectivity, and transference of campaign coverage characteristics to the new medium.

\section{Gatekeeping}

Previous research shows that journalists act as gatekeepers, not just with regard to the news itself but with regard to the profession (Robinson 2006). In enacting their gatekeeping role, journalists exert their authority to select what information achieves significant contribution and to highlight information that is already circulating on social media (a practice known as gatewatching) (Vos 2019). In this paper, we study gatekeeping at the meso level of analysis, comparing what information the two distinct groups of journalists choose to highlight and whose messages they select to pass along to their audiences via the affordances of the platform (linking, replying, and retweeting).

Despite the possibility for participatory newsmaking via social media, empirical evidence has revealed that journalists use Twitter to find story ideas and promote their work, but mainly interact with other journalists and political elites on Twitter, strengthening their gatekeeping (and gatewatching) position (Lawrence et al. 2013; Molyneux and Mourão 2019). Of course, this practice may not be applied consistently across the field. For instance, Lasorsa, Lewis, and Holton (2012) found that journalists working for national newspaper and television news were less inclined than those working for less "elite" outlets to relinquish their gatekeeping role by sharing their stage with other newsmakers and the public. A recent study on large-scale Whatsapp groups also revealed that these semi-public spaces can sustain reciprocity between audiences and reporters in the co-construction of news (Kligler-Vilenchik and Tenenboim 2020), a sharp contrast to prior literature on public spaces such as Twitter.

Therefore, we might expect that more established mainstream journalists would be more likely than non-mainstream journalists to protect their role as gatekeepers on Twitter, indicating fragmented rather than normalized practices between the two groups.

$\mathrm{H} 1$ : Mainstream journalists will be more likely than non-mainstream journalists to protect their role as gatekeepers by (a) linking, (b) replying, and (c) retweeting other journalists.

\section{Objectivity}

The objectivity norm has been a focus of early studies of journalists on Twitter (e.g., Lasorsa, Lewis, and Holton 2012), dictating that newsmaking must focus on reporting the facts without the influence of personal biases, which is often accomplished by providing two sides of a story via a neutral narrative (Schudson 1981). In the 2012 election cycle, findings indicated that journalists on Twitter negotiated the boundaries of objectivity by mixing it with humor and minor commentary as a strategic goal to gain attention but avoided major opinion or bias toward either candidate (Mourão 2016; Mourão et al. 2016; Molyneux, Mourão, and Coddington 2016). In this study, we address how adherence to objectivity might vary between mainstream and non-mainstream reporters. This is particularly relevant as the rejection of objectivity may be a fundamental part of the identity of non-mainstream outlets (Shapiro 2017). 
If forces of normalization are acting most strongly, then Twitter posts from both groups would be more objective and contain less opinion; conversely, differences in the presence of opinion in Twitter posts is evidence of fragmentation. Based on prior studies and the evolution of non-mainstream sites (e.g., Jamieson and Cappella 2008), we expect mainstream reporters to have normalized the platform by adhering closely to objectivity and avoiding critical humor and bias, while non-mainstream reporters would push toward partisan, identity-based coverage.

H2: Mainstream journalists will be more likely than non-mainstream journalists to adhere to objectivity.

\section{Campaign Reporting}

Finally, because the theories of media fragmentation presented here deal primarily with political communication, this study's setting during a campaign is important. Over decades of campaign reporting, journalists have developed a set of standard approaches that serve to impose order on the inherently frenetic and chaotic election season. These include covering campaigns like "horse races" or a game, with a focus on winners, losers and strategy (Cappella and Jamieson 1997); focusing on candidates' characteristics, including background, appearance, and actions; focusing on policy issues as a way of informing voters (Aalberg, Strömbäck, and de Vreese 2012); and a focus on fact-checking (Coddington, Molyneux, and Lawrence 2014). Studies on how these norms translate to Twitter found that reporters focused on candidates' traits and campaign strategies, often adopting the horse race or game frame, but these analyses did not consider how campaign coverage characteristics varied across reporters working for different types of outlets. To the extent that mainstream and non-mainstream journalists jointly adopt these approaches, they are normalizing the new medium using old forms. Conversely, divergence in use of these traditional forms would be evidence of fragmentation. Observing these differences and similarities is particularly important since these sites openly advocate for a different way of doing political journalism.

As such, we ask the following research question:

RQ2:How do mainstream and non-mainstream journalists compare when it comes to campaign coverage characteristics: (a) game frame, (b) candidate characteristics, (c) policy issues, and (d) fact-checking?

\section{Methods}

We conducted a content analysis of tweets and associated digital trace data published by political reporters working for selected mainstream and non-mainstream outlets during the first U.S. presidential debate in 2016. Rather than providing a survey of the field, this piece tests the theoretical proposition that a subset of reporters participating in the national political conversation may have practices that differ from the mainstream. Accordingly, we chose outlets that are prototypes of each group, or representing each group's essential characteristics. For mainstream outlets, this was defined as older, wellestablished news media, excluding new and partisan entrants who might be in liminal spaces. For the non-mainstream outlets, we wanted to ensure that these sites (a) 
defined themselves as news or information providers, (b) publish content that mimics news reports, but are known to publish partisan, sensational, false and/or misleading information, and (c) position themselves as antagonistic to mainstream press. While systematic and purpose-directed, these methodological decisions are naturally subjective, and below we detail the steps necessary to identify political reporters, select groups representative of mainstream and non-mainstream journalism, collect their tweets, and develop a codebook to measure the variables of interest.

\section{Sample}

To identify political reporters covering the 2016 U.S. presidential campaign, we used CisionPoint, a comprehensive database of media contacts in North America that has been used in several studies of journalists (Willard-Hinsely 2010; Lawrence et al. 2013). Because election coverage is the focus of this study, the database was searched for journalists that listed "politics" or "campaign/election" among the topics they covered. Additional searches were performed to ensure inclusion of political reporters in 11 battleground states as identified in a Politico analysis (Mahtesian 2016), and to include political reporters at the most prominent print, broadcast, cable, radio, online and wire news organizations in the U.S. These news organizations' main Twitter handles were also included. Altogether, these searches gathered the Twitter handles of 770 political journalists and 31 news organizations operating in the United States.

First, it was necessary to identify prototypical mainstream and non-mainstream journalists within this selection of political journalists, which was done based on the outlets these journalists work for. For the mainstream sites, we selected journalists working for leading national news outlets and local news outlets in swing states and excluded those working for partisan cable news and online-first outlets (e.g., Fox News, Huffington Post) who may be in a liminal space between these two poles. Here, it is important to note that we are not arguing that journalists working for websites such as Buzzfeed or Huffington Post are partisan-in fact, they may identify themselves as objective, mainstream journalists. However, we opted to follow a more conservative approach, but urge future scholars to expand this work in order to add nuance to the spectrum of political reporting.

Lacking a standard definition of non-mainstream journalism, news outlets were selected based on two criteria: first, inclusion in lists of outlets that publish content that deviates from mainstream norms towards partisan, sensational, false and/or misleading information; and second, confirmation in messaging from these outlets that they view themselves as news providers working outside the mainstream or running counter to it. These lists came from three sources: Wikipedia's "Fake News" list, Buzzfeed's list of hyperpartisan or fake news sites, and the crowd sourced list organized by Professor Melissa Zimdars that is widely used in news literacy courses in the United States. While prior studies on fake news have used a similar methodology (e.g., Grinberg et al. 2019; Mourão and Robertson 2019), it is important to note that the "fake news lists" have faced criticism from right-leaning outlets that argue these resources are biased against conservatives (Harrington 2017). Indeed, the lists do contain a higher number of conservative outlets, but they also feature left-leaning sites such as Occupy Democrats and Blue Nation Review. Taking these three lists together, we believe, provides an adequate compilation of non-mainstream sites that may be relevant for this study. Not all of 
these were represented in our collection of tweets from political journalists. For those that were, to satisfy the second criterion of self-identification, we analyzed the history and selfdescription of the sites to ensure that they described themselves as oppositional to the mainstream press. This left reporters from 13 non-mainstream outlets that cover politics, are influential, and provide a clear anti-mainstream rhetoric. The online appendix to this study lists the outlets selected.

\section{Data Collection}

A custom-built software program was used to harvest data from the selected Twitter accounts during the first U.S. presidential debate on Monday, September 26, 2016. Using programmatic web scraping, it collected account details (e.g., date created, tweet number, follower number) as well as tweet text, timestamp, number of favorites, and any retweets and replies associated with the original post. Every six minutes during the collection period, the program scraped ${ }^{1}$ each monitored account and recorded new data in real time in a separate database. The collection period lasted from one hour before the debate began until three and a half hours after it ended. This produced 5,677 tweets from mainstream journalists in our sample and 796 tweets from non-mainstream journalists. Random samples were taken to select 200 tweets from each of these populations, assuring a representative sample size above the minimum required for a $95 \%$ confidence level that can be compared across groups $(50 \%$ of the sample coming from each of them).

\section{Codebook}

A codebook was developed based on previous studies on normalization and includes variables referring to bias, humor, opinion, game frame, policy issues, candidate characteristics, fact-checking, and engagement. The two authors served as coders. Reliability tests were performed on a random sample of tweets following the recommendation of Riffe, Lacy, and Fico (2006). Krippendorff's alpha scores were used to calculate inter-coder reliability (Hayes and Krippendorff 2007), using ReCal (Freelon 2013). Krippendorff's alphas ranged from 0.77 to 1.00 and the specific values for each variable are described below.

\section{General}

Coders first identified whether the tweet focused on the presidential debate, the presidential election in general, U.S. politics in general, or something else $(a=.83)$. Coders also identified the presence of multimedia elements, including photos, videos and gifs $(a=.85)$.

\section{Gatekeeping}

Journalists' gatekeeping activities were measured by who they linked to, replied to, and retweeted. Then, we recorded if the association was with the journalist herself or her own content, the journalist's own news organization or a co-worker, any other journalist, or a non-journalistic source. For the linking variable, $a=.92$; for the associated tweet variable, $a=.86$. 


\section{Objectivity}

To determine a tweet's level of objectivity, we coded for valence toward each of the candidates and the moderator, presence of humor, and presence of opinion expressed by the journalist who posted the tweet. Valence ( $a=.82$ for Trump, .88 for Clinton) was coded as $0=$ does not mention the candidate, $1=$ negative mention, $2=$ neutral mention, $3=$ positive mention. Humor was determined in response to the question "Regardless of what else is going on, is the reporter trying to be funny?" ( $a=.84$ ). Opinion was defined as evaluations or unattributed commentary not in keeping with the traditional journalistic norm of objectivity $(a=.82)$.

\section{Campaign Characteristics}

Bases on previous studies of political journalists on Twitter, we identified the use of game frame $(a=80)$, mentions of candidate characteristics $(a=.92)$, mentions of policy issues ( $a$ $=.93$ ), and fact checking $(a=.81)$. Each of these were dichotomous variables coded for presence or absence.

Research questions were answered and hypotheses were tested via crosstabulations comparing content characteristics of tweets posted by mainstream and non-mainstream reporters and outlets.

\section{Results}

\section{Data Characteristics}

Considering both mainstream and non-mainstream journalists together for the moment, when it comes to content format, all journalists posted normal tweets the most $(58.7 \%)$. About $29.1 \%$ of tweets had some sort of multimedia like pictures, videos or gifs, and $23.9 \%$ had a hyperlink. When tweets were associated with other users via quotes, replies or retweets, $28.9 \%$ connected to journalists from the same news organization, $37.30 \%$ to journalists working for other news organization, and $28.9 \%$ to non-journalists. Some also used the reply function to themselves as a way of bypassing Twitter's 140-character limitation, a trend that was observed in prior studies on affordances (Molyneux and Mourão 2019).

Tweets that reference a candidate specifically were coded for valence. For Hillary Clinton, $44.6 \%$ of tweets were negative, $41.40 \%$ were neutral and $14 \%$ were positive. For Donald Trump, $49 \%$ of tweets were negative, $43.60 \%$ were neutral and $7.4 \%$ were positive. Two other measures were used to tap into objectivity: opinion and humor. In the tweets analyzed, $33.2 \%$ had opinion and $24.9 \%$ had humor.

Several campaign coverage characteristics identified by prior research were present in this sample: $17 \%$ of tweets used the "game frame," which focuses on who is ahead and who is behind in polls and political strategies used by the campaigns. About $39.8 \%$ of the sample focused on candidate personal characteristics, such as appearance and personal or professional backgrounds. Policy issues were the focus of $24.1 \%$ of the tweets and fact-checking was present in $12.7 \%$. However, not all tweets contain all or even any of campaign coverage variables (26.2\% did not contain any). These were tweets that merely described a scene (e.g., "Views from the spin room for tonight's \#debate"), promoted news stories, shared personal details, etc. Overall, tweets in this sample followed 
traditional patterns of campaign coverage: a focus on personalization and game frame, but also giving some space for the policy issues that were discussed during the debate.

\section{Comparing Mainstream and Non-mainstream Journalists}

\section{Twitter Affordances}

The first research question of this study asks how mainstream and non-mainstream journalists compare when it comes to their use of Twitter affordances. Results displayed in Table 1 reveal a statistically significant difference between the types of tweet posted by mainstream and non-mainstream accounts $\left[X^{2}(3)=19.13\right.$, Cramer's $\left.V=.22, p<.001\right]$, with moderate effects size for $\mathrm{df}=3$ based on Cohen (1988). Mainstream journalists more commonly posted normal, original tweets $(68.7 \%)$ than their non-mainstream counterparts (48.8\%). Conversely, non-mainstream journalists retweeted more (42.8\%) than did mainstream reporters $(23.9 \%)$. $Z$ tests revealed that the two groups did not differ when it comes to their use of replies or quote tweets. For multimedia, mainstream reporters posted pictures, videos or gifs at higher rates $(29.1 \%)$ than non-mainstream $(19.7 \%)\left[X^{2}(1)=4.71\right.$, Cramer's $\left.V=.12, p<.05\right]$.

\section{Gatekeeping}

Our two measures of gatekeeping refer to journalists' use of links and interactions with other users. Links could lead to a story written by themselves (personal promotion) or someone from their organization (organizational promotion), but also by someone from another news organization (institutional promotion) or a non-journalistic website. We posit that mainstream journalists will be more likely than non-mainstream journalists to protect their gatekeeping practices by linking to other journalists $(\mathrm{H} 1)$. We observed a statistically significant difference between linking practices across our two groups $\left[x^{2}(3)=\right.$ 9.15, Cramer's $V=.40, p<.05$ ] (Table 2). Column comparisons via $Z$ tests show that this

Table 1. Format characteristics of tweets posted by mainstream and non-mainstream journalistic accounts.

\begin{tabular}{|c|c|c|c|c|c|c|}
\hline & & Mainst. & Non-mainst. & Total & $x^{2}$ (df) & Cramer's V \\
\hline \multirow[t]{5}{*}{ Tweet type } & & & & & $19.13(3)^{* * *}$ & 0.22 \\
\hline & Normal & $68.7 \mathrm{a} \%$ & $48.8_{\mathrm{b}} \%$ & $58.70 \%$ & & \\
\hline & Retweet & $23.9_{a}$ & $42.8_{b}$ & 33.3 & & \\
\hline & Quotes & $6_{a}$ & $8 a$ & 7.00 & & \\
\hline & Replies & $1.5_{\mathrm{a}}$ & $0.5_{a}$ & 1.00 & & \\
\hline \multicolumn{7}{|l|}{ Multimedia } \\
\hline \multirow{6}{*}{ Links } & (yes) & $29.1_{a}$ & $19.7_{b}$ & $24.40 \%$ & $4.71(1)^{*}$ & 0.12 \\
\hline & & & & & $9.15(3)^{*}$ & 0.4 \\
\hline & Self & $45.8 \mathrm{a} \%$ & $30.4_{\mathrm{a}} \%$ & $40.8 \%$ & & \\
\hline & Organization & 39.6 a & $21.7 \mathrm{a}$ & 33.8 & & \\
\hline & Other media & $10.4 \mathrm{a}$ & $34.8 \mathrm{~b}$ & 18.3 & & \\
\hline & Non-media & $4.2 \mathrm{a}$ & $13.0 \mathrm{a}$ & $7.0 \%$ & & \\
\hline \multirow[t]{5}{*}{ Associated tweet origin } & & & & & $26.35(3)^{* * *}$ & 0.4 \\
\hline & Self & $9.5 \mathrm{a}$ & $1.9_{\mathrm{b}}$ & $4.80 \%$ & & \\
\hline & Organization & $44.4_{a}$ & $19.4_{b}$ & 28.90 & & \\
\hline & Other media & $36.5 \mathrm{a}$ & $37.9_{a}$ & 37.30 & & \\
\hline & Non-media & $9.5 \mathrm{a}$ & $40.8_{b}$ & 28.90 & & \\
\hline
\end{tabular}

\footnotetext{
a,b,c Note: ${ }^{*} p<.05,{ }^{* *} p<.01,{ }^{* * *} p<.001$. The column proportions test table assigns a subscript letter to the categories of the column variable. For each pair of media outlets, the column proportions are compared using a $z$ test. If a pair of values is significantly different $(p<.05)$, the values have different subscript letters assigned to them.
} 
Table 2. Adherence to objectivity and neutrality on tweets posted by mainstream and non-mainstream journalistic accounts.

\begin{tabular}{|c|c|c|c|c|c|c|}
\hline & & Mainst. & Non-mainst. & Total & $x^{2}(\mathrm{df})$ & Cramer's V \\
\hline \multicolumn{7}{|l|}{ Opinion } \\
\hline & (Yes) & $24.5 a \%$ & $41.9_{\mathrm{b}} \%$ & $33.20 \%$ & $13.48(1)^{* * *}$ & 0.19 \\
\hline \multirow[t]{4}{*}{ Clinton valence } & & & & & $53.47(2)^{* * *}$ & 0.54 \\
\hline & Negative & $14.6_{a}$ & $68.3_{\mathrm{b}}$ & $44.60 \%$ & & \\
\hline & Neutral & $64.6_{a}$ & $23.1_{\mathrm{b}}$ & 41.40 & & \\
\hline & Positive & $20.7_{a}$ & $8.7_{\mathrm{b}}$ & 14.00 & & \\
\hline \multirow{4}{*}{ Trump valence } & & & & & $4.26(3)$ & 0.12 \\
\hline & Negative & $48.7_{a}$ & $49.4_{a}$ & $49.00 \%$ & & \\
\hline & Neutral & $47_{a}$ & $39.1_{a}$ & 43.60 & & \\
\hline & Positive & $4.3_{a}$ & $11.5_{a}$ & 7.40 & & \\
\hline \multirow[t]{2}{*}{ Humor } & & & & & & \\
\hline & (yes) & 18.90 & 30.80 & 24.90 & $7.50 * *$ & 0.14 \\
\hline
\end{tabular}

difference lies in their willingness to post links to content produced by other news outlets: $34.8 \%$ of the non-mainstream links led to news content produced by a news organization other than the one where the journalist worked, three times more often than the links posted by mainstream journalists $(10.4 \%)$. This evidence suggests that non-mainstream reporters are less committed to promoting their own organization, opening the gates to content produced by others.

For retweets, quote tweets and replies, we also coded for the "associated" tweet; i.e., who sent the original tweet that was retweeted, replied to or quoted. There were significant differences between mainstream and non-mainstream journalists $\left[x^{2}(3)=26.35\right.$, Cramer's $\mathrm{V}=.40, p<.001]$. Results show that mainstream journalists are more likely to reply to themselves in efforts to bypass Twitter's character limit (9.5\%), as compared with non-mainstream reporters (1.9\%). Similarly, mainstream journalists refer to other users in their organization more (44.4\%) than non-mainstream reporters (19.4\%). Conversely, non-mainstream reporters interact with those outside the journalistic bubble a lot more $(40.8 \%)$ than did mainstream journalists (9.5\%). $Z$ tests did not show differences when it comes to interacting with reporters at other organizations, which happened in about $37 \%$ of the associated tweets for both groups. The effects size for both measures of gatekeeping are large (Cramer's $V=.40$ ) based on the guidelines proposed by Cohen (1988). H1 was supported.

\section{Objectivity and Neutrality}

$\mathrm{H} 2$ predicts that mainstream journalists will be more likely to adhere to objectivity than non-mainstream journalists. Not surprisingly, non-mainstream accounts displayed opinion significantly more often $(41.9 \%)$ than mainstream $(24.5 \%)\left[X^{2}(1)=13.48, p<.001\right]$.

When the candidates were mentioned, we also measured the valence of coverage. Results show a statistically significant difference in portrayals of Hillary Clinton, with non-mainstream coverage being more negative (68.3\%) than mainstream (14.6\%). Mainstream journalists tended to portray the Democratic candidate using a neutral tone $(64.6 \%)$, more often than non-mainstream journalists $(23.1 \%)$. Only $8.7 \%$ of the tweets mentioning Clinton posted by non-mainstream journalists had a positive tone, which is 
significantly smaller than the $20.7 \%$ from the mainstream press $\left[x^{2}(1)=53.47, p<.001\right]$. This is also the largest difference between the two groups (Cramer's $V=.54$ ).

Interestingly enough, these differences are not present when it comes to portrayal of Republican candidate Donald Trump, with both groups tending to portray him negatively (48.7\% for mainstream, $49.4 \%$ for non-mainstream) or neutral (47\% for mainstream, $39.1 \%$ for non-mainstream). Positive portrayal was rare for both groups, present in $4.3 \%$ of mainstream coverage and $11.5 \%$ of non-mainstream. These differences were not statistically significant. It was common, for example, for the same non-mainstream journalist to tweet an original post attacking Clinton, and seconds later retweet a negative post about Trump.

Our codebook also measured moderator valence to tap into portrayals of the work of Lester Holt during the debate. However, crosstabulations could not be calculated because only 4 tweets posted by mainstream reporters mentioned the moderator, which would violate chi-square assumptions of at least 5 observations per category. Non-mainstream accounts, however, mentioned Holt in $14.9 \%$ of tweets, and those mentions were overwhelmingly negative (83.3\%).

Prior research also identified humor as another form of deviation from the objectivity norm (Holton and Lewis 2011). In this sample, non-mainstream journalists used humor more frequently $(30.8 \%)$ than mainstream (18.9\%) and the difference was statistically significant $\left[X^{2}(1)=7.50\right.$, Cramer's $\left.V=.14, p<.01\right]$. Hypothesis 2 posed that mainstream journalists will be more likely to adhere to objectivity than non-mainstream journalists. Because mainstream reporters used opinion and humor less, $\mathrm{H} 2$ was supported.

We observed some additional patterns in these associated tweets from a qualitative perspective. Non-mainstream reporters interacted more with audiences by using opinion and humor, often sharing partisan viewpoints and asking for their opinion. These audience members were regular people, partisan activists and fringe politicians. Even when interacting with other journalists, non-mainstream journalists exhibited different behavior than their mainstream colleagues. Non-mainstream users split their interactions roughly equally between mainstream and non-mainstream journalists. Mainstream journalists, on the other hand, rarely (in only two cases) interacted with non-mainstream journalists. Instead, mainstream journalists more frequently interacted with other mainstream journalists or those working at digital-native publications, such as HuffingtonPost, BuzzFeed, and Vox.

\section{Campaign Coverage Characteristics}

Our final research question asks about how campaign coverage characteristics varied between mainstream and non-mainstream reporters based on measures found in prior studies on political communication on legacy media (Crouse 1973; Cappella and Jamieson 1997) and on Twitter (Lawrence et al. 2013).

Results show that both groups focus on candidate characteristics, such as appearance and personal background, at similar levels (36.2\% for mainstream and $43.4 \%$ for non-mainstream) $\left[X^{2}(1)=2.14\right.$, Cramer's $V=.07$, n.s.]. Similarly, the number of tweets focusing on policy issues was almost identical for both groups $(\sim 24 \%)\left[X^{2}(1)=0.004\right.$, Cramer's V $=.003$, n.s.]. Fact-checking was uncommon, accounting for $12.2 \%$ of mainstream tweets and $13.2 \%$ of non-mainstream $\left[x^{2}(1)=.08\right.$, Cramer's $V=.01$, n.s.]. However, when it comes to "game frame," we found that tweets from the mainstream press were 
significantly more likely to have the frame (21.4\%) than those posted by non-mainstream journalists $(12.60 \%)\left[X^{2}(1)=5.41\right.$, Cramer's $\left.V=.14, p<.05\right]$.

\section{Discussion}

This study set out to investigate forces of normalization and fragmentation using Twitter as a locus for comparing the practices of mainstream and non-mainstream reporters. Beyond determining whether theoretically expected and organizationally professed differences in ethos are actually observable in practice, this study helps identify which characteristics are part of mainstream journalism's core and which are more associated with its fringe elements.

Our results indicate that mainstream journalists follow traditional journalistic norms more closely, with small deviations from objectivity via humor and opinion, which is consistent with prior studies that observed these deviations in journalism as a whole (Lasorsa, Lewis, and Holton 2012; Molyneux, Mourão, and Coddington 2017). Non-mainstream reporters deviate more widely from objectivity by employing major opinion more frequently, and this opinion was largely negative. While both groups treated Donald Trump the same way (negatively), non-mainstream journalists harshly criticized Clinton and her record, contested her statements and made fun of her. Non-mainstream journalists were also extremely critical of debate moderator Lester Holt, while mainstream journalists hardly mentioned him.

The biggest differences between the groups analyzed were in gatekeeping practices. Consistent with prior studies (Lawrence et al. 2013), mainstream journalists in this sample were much more reluctant to open the gates for participatory newsmaking, rarely linking or interacting with those outside the journalistic bubble. Conversely, nonmainstream reporters frequently interacted with non-journalistic users on Twitter and hyperlinked to content produced by other non-mainstream organizations or non-journalistic entities. These interactions included information-seeking, humor and opinion. Perhaps participatory newsmaking happens because non-mainstream reporters are outside of the establishment and not subjected to the same social pressures. It could also be that as newcomers they have limited resources to produce original content, so they resort to crowdsourcing and linking to outside content. Future studies should investigate these interactions and classify the types of outside users that are part of non-mainstream news engagement. Qualitatively, we observed that these accounts interact with both traditional news outlets and politicians, but also with other partisan sites, fringe activists, and the average public.

Of all the variables measured here, evidence of normalization is most present when it comes to campaign coverage characteristics. We found that both groups analyzed employ similar patterns of campaign coverage, most notably a focus on candidate characteristics, policy issues and fact-checking. The only difference between the two groups was found for the game frame, which is less common for non-mainstream outlets, but frequently employed by mainstream media to fend off accusations of bias (Cappella and Jamieson 1997). As noted above, non-mainstream reporters already employ more opinion in their tweets, and therefore may not be concerned with projecting objectivity.

The findings we present here add to recent work on "fake news" and hyperpartisan media (e.g., Grinberg et al. 2019; Haller, Holt, and de La Brosse 2019; Tandoc, Jenkins, 
and Craft 2019). On the one hand, the literature on normalization, institutionalization and ecological assimilation (Lowrey 2012) suggests that new entrants in the field seek stability and acceptance, thus adopting practices of established actors. On the other hand, recent work on entertainment news, "fake news," and partisan media suggest a more nuanced view of this process, with non-mainstream producers adopting hybrid approaches that discursively integrate elements endogenous and exogenous to professional reporting (Baym 2010; Tandoc, Lim, and Ling 2018, Mourão and Robertson 2019). In particular, while "fake news" appropriate the look and the feel of real news (Tandoc, Lim, and Ling 2018), their content remains strategically partisan and in line with clear political and economic goals (Guess, Nyhan, and Reifler 2018). This is particularly true of conservative sites that form a highly mature media ecosystem appealing to partisan audiences disenchanted with mainstream media, which they perceive to have a liberal bias (Jamieson and Cappella 2010; Hemmer 2016; Figenschou and Ihlebæk 2019; Haller, Holt, and de La Brosse 2019). Our findings echo this literature, with non-mainstream reporters on Twitter adopting certain formats of mainstream campaign reporting, while strategically focusing on partisan content and engagement with audiences.

This study is limited by its use of cross-sectional data during a single event, essentially providing a snapshot of a rapidly changing situation. We selected the presidential debate because it is a defining event of heightened media attention and because prior literature on journalists on Twitter also uses debates as the loci of study (e.g., Coddington, Molyneux, and Lawrence 2014; Mourão 2016). Thus, our results are tightly connected to a staged political event and may not be generalizable to campaign coverage as a whole. Because we are focusing on the mainstream vs. non-mainstream comparison, and because our nonmainstream sites all have a national scope, we did not conduct an analysis comparing national/regional mainstream sites, which had been the focus of prior work (e.g., Lasorsa, Lewis, and Holton 2012). Future research may study non-mainstream local outlets that have bloomed leading up to the 2020 election (see Levin 2019).

Additionally, this is not a comprehensive study of non-mainstream news organizations, but a study designed to measure whether theoretically expected differences were observable in practice. We therefore opted to pull content only from prototypical outlets from both groups. In other words, our mainstream media list contains older, established outlets that cannot be considered new entrants to the field. Conversely, we established strict criteria to ensure our non-mainstream outlets both positioned themselves as providers of news and presented a clear anti-mainstream rhetoric. While we acknowledge these methodological decisions were dictated by the theoretical inquires at hand, we hope this study provides a starting point for understanding the divisions that have arisen in contemporary journalism and the ways in which new actors converge with the mainstream press when covering politics.

Finally, we acknowledge that there might be an uneasiness associated with our decision to consider these specific non-mainstream producers as part of the field of journalism. As media scholars, such a decision could further legitimize these actors in a way that might not be normatively desirable. We want to highlight that our selection is not based on the argument that these producers have achieved normative (or moral) legitimacy (Lowrey 2012); that is, that they fit with social norms and are generally seen as beneficial. Nonetheless, we opted to use this framework because we believe that studying the challenges posed by these non-mainstream producers can be informed by our knowledge 
of what happened when more "benign" formats challenged the field; e.g., fact-checking sites (Lowrey 2017), bloggers (Singer 2005; Lowrey 2012), and social media practices (Lasorsa, Lewis, and Holton 2012), just to cite a few.

The results presented here suggest divergence in practices of objectivity and gatekeeping, and convergence in campaign coverage practices. Mainstream reporters insulate themselves and hold to traditional norms, while non-mainstream journalists offer openly partisan interpretations and seek out participation and engagement, often from people who share their viewpoints. But the key contribution of this study is to provide empirical evidence of what many have intuitively sensed and scholars have predicted: The field of journalism is experiencing entropy driven by fragmentation of professional practice, with mainstream reporters increasingly isolated from newer, openly partisan actors who cover the same events with the same foci, but without relying on norms of objectivity and gatekeeping.

\section{Note}

1. Web scraping extracts data from the published version of a website and does not use any application programming interface (API) that may underlie the page or platform.

\section{Disclosure Statement}

No potential conflict of interest was reported by the author(s).

\section{ORCID}

Rachel R. Mourão (1D) http://orcid.org/0000-0001-8229-7247

Logan Molyneux (D) http://orcid.org/0000-0001-7382-3065

\section{References}

Aalberg, T., J. Strömbäck, and C. H. de Vreese. 2012. "The Framing of Politics as Strategy and Game: A Review of Concepts, Operationalizations and Key Findings." Journalism: Theory, Practice \& Criticism 13 (2): 162-178.

Araújo, B., and H. Prior. 2020. "Framing Political Populism: The Role of Media in Framing the Election of Jair Bolsonaro." Journalism Practice, 1-17.

Baym, G. 2010. From Cronkite to Colbert: The Evolution of Broadcast News. Boulder, CO: Paradigm Publishers. p. 5.

Bennett, W. L., and S. lyengar. 2008. "A New Era of Minimal Effects? The Changing Foundations of Political Communication." Journal of Communication 58: 707-731.

Blumler, J. G. 2016. "The Fourth Age of Political Communication." Politiques de Communication 6 (1): 19-30.

Blumler, J. G., and D. Kavanagh. 1999. "The Third Age of Political Communication: Influences and Features." Political Communication 16 (3): 209-230.

Bourdieu, P. 1986. "The Forms of Capital." In Handbook of Theory and Research for the Sociology of Education, edited by P. Bourdieu, and J. G. Richardson, 241-258. New York: Greenwood Publishing Group.

Cappella, J. N., and K. H. Jamieson. 1997. Spiral of Cynicism: The Press and the Public Good. New York: Oxford University Press.

Carlson, M. 2018. "Fake News as an Informational Moral Panic: The Symbolic Deviancy of Social Media During the 2016 US Presidential Election." Information, Communication \& Society 23 (3): 374-388. 
Carlson, M., and S. C. Lewis, eds. 2015. Boundaries of Journalism: Professionalism, Practices and Participation. New York: Routledge.

Chadwick, A. 2017. The Hybrid Media System: Politics and Power. New York: Oxford University Press.

Chaffee, S., and M. Metzger. 2001. "The End of Mass Communication?." Mass Communication and Society 4: 365-379.

Coddington, M. 2012. "Defending a Paradigm by Patrolling a Boundary: Two Global Newspapers' Approach to WikiLeaks." Journalism and Mass Communication Quarterly 89 (3): 377-396.

Coddington, M., L. Molyneux, and R. G. Lawrence. 2014. "Fact Checking the Campaign: How Political Reporters Use Twitter to Set the Record Straight (or Not)." The International Journal of Press/Politics 19 (4): 391-409.

Cohen, J. 1988. Statistical Power Analysis for the Behavioral Sciences. Hillsdale: Lawrence Earlbaum Associates. pp. 2.

Cook, T. E. 1998. Governing with the News: The News Media as a Political Institution. Chicago: University of Chicago Press.

Cook, T. E. 2006. "The News Media as a Political Institution: Looking Backward and Looking Forward." Political Communication 23 (2): 159-171. doi:10.1080/10584600600629711.

Crouse, T. 1973. The Boys on the Bus. New York: Ballantine.

Djerf-Pierre, M., M. Ghersetti, and U. Hedman. 2016. "Appropriating Social Media: The Changing Uses of Social Media among Journalists Across Time." Digital Journalism 4: 849-860.

Djerf-Pierre, M., and A. Shehata. 2017. "Still an Agenda Setter: Traditional News Media and Public Opinion during the Transition from Low to High Choice Media Environments." Journal of Communication 67 (5): 733-757.

Figenschou, T. U., and K. A. Ihlebæk. 2019. “Challenging Journalistic Authority: Media Criticism in FarRight Alternative Media." Journalism Studies 20 (9): 1221-1237.

Freelon, D. 2013. "ReCal OIR: Ordinal, Interval, and Ratio Intercoder Reliability as a Web Service." International Journal of Internet Science 8 (1): 10-16.

Grinberg, N., K. Joseph, L. Friedland, B. Swire-Thompson, and D. Lazer. 2019. "Fake News on Twitter During the 2016 U.S. Presidential Election." Science 363 (6425): 374-378.

Guess, A., B. Nyhan, and J. Reifler. 2018. Selective Exposure to Misinformation: Evidence from the Consumption of Fake News During the 2016 US Presidential Campaign. https://www. dartmouth.edu/ nyhan/fake-news-2016.pdf.

Gutsche Jr, R. E., and K. Hess. 2018a. "Contesting Communities: The Problem of Journalism and Social Order." Journalism Practice 12 (2): 136-145.

Gutsche, R. E. Jr, and K. Hess. 2018b. Geographies of Journalism: The Imaginative Power of Place in Making Digital News. Abingdon: Routledge.

Haller, A., K. Holt, and R. de La Brosse. 2019. "The Other Alternatives: Political Right-Wing Alternative Media." Journal of Alternative and Community Media 4 (1): 1-6.

Harlow, S., and T. J. Johnson. 2011. "The Arab Spring Overthrowing the Protest Paradigm? How The New York Times, Global Voices and Twitter Covered The Egyptian Revolution." International journal of Communication 5: 16.

Harrington, E. 2017. "Fake Professor Calls Free Beacon 'Fake News'." The Washington Free Beacon. Accessed March 20, 2018. https://freebeacon.com/.

Hayes, A. F., and K. Krippendorff. 2007. "Answering the Call for a Standard Reliability Measure for Coding Data." Communication Methods and Measures 1 (1): 77-89.

Hemmer, N. 2016. Messengers of the Right: Conservative Media and the Transformation of American Politics. Politics and Culture in Modern America. Philadelphia: University of Pennsylvania Press.

Hermida, A., S. C. Lewis, and R. Zamith. 2014. "Sourcing the Arab Spring: A Case Study of Andy Carvin's Sources on Twitter During the Tunisian and Egyptian Revolutions." Journal of Computer-Mediated Communication 19 (3): 479-499.

Holbert, R. L., R. K. Garrett, and L. S. Gleason. 2010. "A New Era of Minimal Effects? A Response to Bennett and lyengar." Journal of Communication 60 (1): 15-34.

Holton, A. E., and S. C. Lewis. 2011. "Journalists, Social Media, and the Use of Humor on Twitter." Electronic Journal of Communication 21 (1/2). http://www.cios.org/EJCPUBLIC/021/1/021121.html. 
Jamieson, K. H., and J. N. Cappella. 2008. Echo Chamber: Rush Limbaugh and the Conservative Media Establishment. Oxford: Oxford University Press.

Jamieson, K. H., and J. N. Cappella. 2010. Echo Chamber: Rush Limbaugh and the Conservative Media Establishment. Oxford: Oxford University Press.

Kligler-Vilenchik, N., and O. Tenenboim. 2020. "Sustained Journalist-Audience Reciprocity in a Meso New-Space: The Case of a Journalistic WhatsApp Group." New Media \& Society 22 (2): 264-282.

Lasorsa, D. L., S. C. Lewis, and A. E. Holton. 2012. "Normalizing Twitter: Journalism Practice in an Emerging Communication Space." Journalism Studies 13 (1): 19-36.

Lawrence, R. G., L. Molyneux, M. Coddington, and A. Holton. 2013. "Tweeting Conventions: Political Journalists' Use of Twitter to Cover the 2012 Presidential Campaign." Journalism Studies 15 (6): 1-18.

Levin, D. 2019. "Mimicking Local News, a Network of Michigan Websites Pushes Politics." The New York Times. October 21. https://www.nytimes.com/2019/10/21/us/michigan-metric-medianews.html.

Lewis, S. C. 2012. "The Tension Between Professional Control and Open Participation: Journalism and Its Boundaries." Information, Communication and Society 15 (6): 836-866.

Lowrey, W. 2012. "Journalism Innovation and the Ecology of News Production: Institutional Tendencies." Journalism and Communication Monographs 14 (4): 214-287.

Lowrey, W. 2017. "The Emergence and Development of News Fact-Checking Sites: Institutional Logics and Population Ecology." Journalism Studies 18 (3): 376-394.

Mahtesian, C. 2016. "What Are the Swing States in 2016?" Politico, June 15.

Molyneux, L., A. Holton, and S. C. Lewis. 2018. "How Journalists Engage in Branding on Twitter: Individual, Organizational, and Institutional Levels." Information, Communication \& Society 21 (10): 1386-1401.

Molyneux, L., and R. R. Mourão. 2019. “Political Journalists' Normalization of Twitter: Interaction and New Affordances." Journalism Studies 20 (2): 248-266.

Molyneux, L., R. R. Mourão, and M. Coddington. 2016. “U.S. Political Journalists' Use of Twitter: Lessons from 2012 and a Look Ahead." In Twitter and Elections Around the World: Campaigning in 140 Characters or Less, edited by R. Davis, C. Holtz-Bacha, and M. R. Just, 43-56. New York: Routledge.

Mourão, R. R. 2016. “The Boys on the Timeline: Political Journalists' Use of Twitter for Building Interpretive Communities." Journalism: Theory, Practice \& Criticism 16 (8): 1107-1123.

Mourao, R. R., and W. Chen. 2020. "Covering Protests on Twitter: The Influences on Journalists' Social Media Portrayals of Left-and Right-Leaning Demonstrations in Brazil." The International Journal of Press/Politics 25 (2): 260-280.

Mourão, R. R., T. Diehl, and K. Vasudevan. 2016. "I Love Big Bird: How Journalists Tweeted Humor During the 2012 Presidential Debates." Digital Journalism 4 (2): 211-228.

Mourão, R. R., and C. T. Robertson. 2019. "Fake News as Centrifugal Diversification: A Content Analysis of Sites that Publish False, Misleading, Hyperpartisan and Sensational Information." Journalism Studies 20 (14): 2077-2095.

Parks, P. 2019. "Covering Trump's 'Carnival': A Rhetorical Alternative to 'Objective' Reporting." Journalism Practice 13 (10): 1164-1184.

Riffe, D., S. Lacy, and F. Fico. 2006. Analyzing Media Messages: Using Quantitative Content Analysis in Research. New York: Routledge.

Robertson, C. T., and R. R. Mourão. 2020. "Faking Alternative Journalism? An Analysis of SelfPresentations of "Fake News" Sites." Digital Journalism online first.

Robinson, S. 2006. "The Mission of the J-Blog: Recapturing Journalistic Authority Online." Journalism: Theory, Practice \& Criticism 7 (1): 65-83.

Robinson, S. 2010. "Traditionalists vs. Convergers: Textual Privilege, Boundary Work, and the Journalist-Audience Relationship in the Commenting Policies of Online News Sites." Convergence: The International Journal of Research Into New Media Technologies 16 (1): 125-143.

Robinson, S. 2017. Networked News, Racial Divides: How Power and Privilege Shape Public Discourse in Progressive Communities. New York, NY: Cambridge University Press.

Ryfe, D. M. 2016. Journalism and the Public. Malden: Polity Press. 
Schudson, M. 1981. Discovering the News: A Social History of American Newspapers. New York: Basic Books.

Schultz, I. 2007. "The Journalistic Gut Feeling: Journalistic Doxa, News Habitus and Orthodox News Values." Journalism Practice 1 (2): 190-207.

Scott, W. R. 2008. Institutions and Organizations: Ideas and Interests. Thousand Oaks: Sage.

Shapiro, B. 2017. "A Field Guide to Harvard's Field Guide on 'Fake News'." In: National Review. Accessed October 3, 2017. https://www.nationalreview.com/.

Shoemaker, P., and S. D. Reese. 2014. Mediating the Message in the 21st Century: A Media Sociology Perspective. New York: Taylor \& Francis Group.

Singer, J. B. 2005. "The Political j-Blogger: 'Normalizing' a New Media Form to Fit Old Norms and Practices." Journalism: Theory, Practice \& Criticism 6 (2): 173-198.

Swift, A. 2016. "Americans' Trust in Mass Media Sinks to New Low." Gallup, September 14.

Tandoc Jr, E. C., J. Jenkins, and S. Craft. 2019. "Fake News as a Critical Incident in Journalism." Journalism Practice 13 (6): 673-689.

Tandoc Jr, E. C., Z. W. Lim, and R. Ling. 2018. "Defining 'Fake News': A Typology of Scholarly Definitions." Digital Journalism 6 (2): 137-153. doi:10.1080/21670811.2017.1360143.

Vos, T. 2019. "Journalists as Gatekeepers." In The Handbook of Journalism Studies, edited by K. WahlJorgensen, and T. Hanitzsch, 90-104. New York: Routledge.

Willard-Hinsley, Amber. 2010, November 1. "At the Crossroads of Crisis: Newspaper Journalists' Struggle to Redefine Themselves and Their Work as Their Organizations and the Profession Change." University of Texas at Austin. http://gradworks.umi.com/34/29/3429012.html

Zelizer, B. 1993. "Has Communication Explained Journalism?" Journal of Communication 43 (4): 80-88. 